San Jose State University

From the SelectedWorks of Peter J. Haas

2016

\title{
Impact on Bus Ridership from Changes in a Route's Span of Service
}

Jacob Simmons

Peter J Haas, San Jose State University

Available at: https://works.bepress.com/peter_haas/91/ 
Jacob Simmons

48921 Jaquita Avenue, Las Vegas, NV 89149

$5 \quad$ Tel: 702-287-8579; Email: Jacob.b.simmons@gmail.com

6

Dr. Peter J. Haas, Corresponding Author

Education Director, Mineta Transportation Institute

$210 \mathrm{~N} 4^{\text {th }}$ St, $4^{\text {th }}$ Flr, San Jose, CA 95112-0219

Tel: 408-924-5691; Fax: 408-924-7565; Email: peter.haas@ sjsu.edu

11

12

13

14

Word count: 5,630 words text +2 tables $\times 250$ words $($ each $)+2$ figures $\times 250$ words $($ each $)=$ 6,772

17

18

19

20

21

22

23

Submitted July 31, 2015 


\begin{abstract}
25 Ridership response to bus route span of service changes -the start time of the first trip to the end 26 time of the last trip each day -is examined specifically for hours that were not altered by a span

27 of service change. Data were obtained for 39 routes from nine western United States transit

28 agencies that experienced span of service changes without any other types of changes, enabling

29 the largest known analysis of such data from American transit systems. Results demonstrate that

30 bus routes that received a span of service increase experienced a $12.4 \%$ increase in ridership

31 during unaltered hours, or a 3.4\% increase in ridership during unaltered hours after adjusting for

32 systemwide ridership changes. Bus routes that received a span of service decrease experienced a

$330.1 \%$ decrease in ridership during unaltered hours or a $1.5 \%$ decrease in ridership during

34 unaltered hours after adjusting for systemwide ridership changes. Possible reasons for ridership

35 increases following a span decrease are explored. The agency that implemented the largest

36 collection of span increases simultaneously experienced the largest percent increase in ridership

37 during unaltered hours, exhibiting similarity to another large span increase outside the United

38 States, indicating a potential synergistic effect that warrants additional research. Other factors

39 present in routes that experienced relatively strong ridership responses during unaltered hours are

40 also presented for agencies to consider when evaluating possible service span changes.
\end{abstract}

Keywords: transit, bus, span of service, service span, ridership 
Along with frequency, bus route span of service -also known as service span, hours of operation, or operating hours - determines when transit service operates. All other things being equal, a bus route with a longer span of service can accommodate a wider variety of users and trip purposes than a route with a shorter span of service (1). However, span of service also directly affects cost, as most costs associated with bus service increase with each hour of service added. Therefore, transit agencies must give careful consideration to determining the most appropriate span of service for each bus route, based on the needs of the customers and communities the route serves, within the context of available funding.

The economic recession of the late 2000s brought about a number of bus service reductions, frequently affecting the span of service for bus routes in many cities and reducing transit service for customers that used affected bus routes during the eliminated hours. The elimination of bus service during certain hours may force affected patrons to either make potentially major life changes -in the form of a new job, new work schedule, or new residence or switch modes, which may not necessarily be practical for some affected persons. Similarly, a span of service increase that makes bus service available during hours in which it was previously unavailable creates new options for existing transit users, especially transit-dependent customers, and potentially attracts new customers that were previously unable to use bus service.

Ridership lost during eliminated hours, or gained during added hours, represents direct impacts of a span of service change. When transit managers consider a span of service decrease, it is generally only these customers that are likely to be affected (2). However, there may also be indirect impacts from such changes that are less obvious and less understood. For example, will afternoon ridership be affected if late night bus service is curtailed, as riders working swing shifts in restaurants, grocery stores, customer service call centers, or other employment venues are no longer able to make their return trip via bus service? Will fewer trips be made on buses in the early evening if late evening service is eliminated? Similarly, will ridership in the early afternoon increase if bus service starts an hour or two earlier in the morning because those that must be at work at 5 a.m. or 6 a.m. are now able to make use of bus service and therefore will complete a return trip during afternoon hours, a time when service had previously been offered? Does overall ridership on a bus route increase by more than the additional ridership gained during new hours of service if the span of service is increased, and if so, to what extent? In a related scenario, if a bus route that previously operated until midnight is reduced to ending at 10 p.m., how will ridership during 9 p.m. and 10 p.m. be affected? Will ridership during these hours increase -because customers that were previously using the service at $11 \mathrm{p} . \mathrm{m}$. and midnight are able to adjust their schedules and use the service at 10 p.m. -or will it decrease because of anxiety amongst customers traveling on what now became the last trip of the night, leading those customers to seek another mode due to the lost assurances of later "lifeline" service in case of delays or changes in their schedules? How will ridership earlier in the evening be affected, when the outgoing portion of some trips are taking place?

These types of potential indirect ridership impacts due to a span of service change are the focus of this research paper. The answers to these sorts of questions have a substantial impact on how transit agencies should approach potential span of service changes, which often occur either amid other service cuts designed to address budgetary shortfalls or in the larger context of improving service for customers. Whether unaltered hours experience a change in ridership is an important question to agencies operating bus service, but it is ultimately even more important to bus riders. 
Data used in this study was from transit systems in the western and southwestern United States, during the period from 1997 to 2014, although the findings are likely relevant to other regions. Due to possible differences in the market response to rail, Bus Rapid Transit, and other transit modes, this research is limited to traditional bus mode span of service changes.

\section{LITERATURE REVIEW}

Existing research on the broader topic of bus route span of service features several limitations. Much of the existing knowledge on the subject relies on examples or case studies that are now several decades old or from countries other than the United States, contains span of service changes mixed with other types of service enhancements or reductions, or is not focused specifically on bus service. Often, previous studies analyzed only to what extent total ridership on a bus route had increased, and not specifically whether the increases in ridership occurred during hours of service that had been added or during time periods that were not directly affected -unaltered- by a span increase. Some of the most notable publications regarding span of service offer quality of service indicators based on the number of hours that service operates each day and note that a longer span of service allows a larger range of trip purposes to be served, but do not discuss potential ridership impacts that changes in span of service may have on unaltered hours (1). Few studies have addressed the question of how span of service changes affects unaltered hours, and none that are exclusive to span of service ridership impacts have focused on cities in the United States.

Several studies cite the role that span of service plays in determining whether transit service is available (3). Research from the Florida Department of Transportation calculates transit Level of Service (LOS) using span of service and frequency (4). Similarly, the TCRP Transit Capacity and Quality of Service Manual also provides guidance for span of service LOS calculations (5). Crockett emphasizes that span of service also determines transfer availability (6); even where many routes operate a long service span, if one route in a transit customer's commute is not operating at a given time, the customer will either choose not to board any of the transit routes needed to complete that trip or will otherwise be stranded at a transfer point. Each of these sources demonstrate that span of service is the temporal equivalent to service coverage.

In many situations, customers may not be satisfied with the span of service decisions being made by transit agencies, specifically in terms of how accessibility is impacted. A study of customer satisfaction with transit systems in Florida identified span of service as one of the top importance factors where improvement was needed for several transit agencies (7). One of five recommendations from the study was for systems to consider increasing evening span of service. Similarly, a survey of transit planners and providers in Connecticut ranked 'more frequent service and better service span' as the most important feature for assessing transit accessibility (8). A 2007 TCRP report also noted that a mismatch between services provided and those desired by customers, such as a mismatched span of service, can be amongst the reasons for lower-than-expected transit usage. Still, despite some documented dissatisfaction and demand from customers and the recognized role that span of service plays in transit accessibility, of 86 operating or service adjustment projects, only four involved an increased span of service (9). More popular types of service improvements included increased route coverage, route restructuring, and passenger facility improvements.

Surprisingly, ridership response to span of service changes has received little attention in the form of empirical research addressing the United States in the past twenty years (10). The only relatively recent and detailed examination of the ridership response to span of service 
changes in a western or southwestern United States location came from Santa Clarita, California (3). However, this case included other significant service improvements; a major challenge in determining the specific ridership response to span of service changes is that the effect is often not identified separately from other types of changes, especially frequency changes. Two additional examples of a 'significant' ridership increase during unaltered hours due to the introduction of evening or weekend service are also provided from the Bellingham, Washington and Dallas, Texas areas, but no specific figures or percentages are provided (3).

Several relevant studies based on non-US systems have been completed. In 2008, Athens, Greece extended metro train service by two hours (from 12:30 to 2:30 a.m.) on Friday and Saturday nights as part of a two month pilot program. The study found that in addition to ridership added during the extended hours, ridership increased during unaltered hours prior to the extended service (11). Ridership increased by approximately $15 \%$ between 8 and 10 p.m. and by approximately $45 \%$ between 10 p.m. and midnight -time periods that were unaltered, experiencing no change in service.

Two closely related case studies from Melbourne, Australia (an urbanized area with 3.6 million inhabitants) provide some of the best and most detailed examinations of span of service changes affecting bus ridership during unaltered hours. In 2007, 72 bus routes operated until at least 9 p.m., seven days a week; by 2008, 111 bus routes met this standard. Currie \& Loader (2009) analyzed 22 of Melbourne's bus routes that received no improvements other than a significant span of service increase (10). The study found that ridership grew substantially during both evening (recently extended) and daytime (unaltered) hours. Weekday ridership increased by a total of about $3.3 \%$ on the studied routes, and about $47 \%$ of the weekday ridership increase occurred before 5 p.m., during which time all routes were previously in operation and were unaltered by the implemented service improvements. Daytime ridership growth was particularly strong on Saturday afternoons and throughout the day on Sundays. Using travel survey data and the ridership growth percentages by hour for each day type, the study authors conclude with the strengthened hypothesis that extending the evening service span on bus routes increased ridership by encouraging more daytime outbound trips using the bus, since return evening trips could be captured by the later span of service.

Loader \& Stanley (2009) chose to analyze routes as a group based on their previous ending times on Saturdays (12). Of the 26 routes in the study, routes that previously ended the earliest displayed the most dramatic ridership increases during unaltered hours -in some cases, more than doubling -whereas routes that previously ended later experienced more modest increases during earlier hours, such as an average $10 \%$ ridership gain during afternoon hours when routes that previously ended between 6 and 7 p.m. received a span increase. The report finds that many passengers making trips during the day require service until at least 7 p.m. for a return trip, while routes operating beyond 7 p.m. are growing demand for evening service but having little or no effect on daytime travel.

\section{METHODOLOGY}

To determine the extent of any impacts to ridership during unaltered hours due to a span of service change, data for detailed route ridership necessary from both before and after a span of service change. Data procured for this study varied by agency, and included bus fare boxes, Automatic Passenger Counters (APCs), and manual counts by operators. Although data for multiple months before and after an applicable span change would have been ideal, in practice, data for multiple months or by season was obtained only from some agencies, while others were 
only able to provide one month's worth of data from prior to a span change and one month's worth of data from after a span change. To avoid seasonality effects on ridership, data from the same calendar month(s) or season prior to and following a span change was obtained for all analyzed agencies.

Other types of changes, such as routing changes, fare changes, frequency changes, and significant rescheduling to improve on-time performance, may also affect ridership on a route undergoing a span of service change. For this reason, many routes that experienced span of service changes for which data was provided or could have been provided were rejected due to frequency, routing, or major scheduling changes that occurred simultaneously. Conversely, the routes selected for analysis were subject to very minimal or no changes other than span of service adjustments.

Additionally, to control for broader ridership trends, patronage on routes affected by a span of service change was compared to the ridership on all bus routes in a transit system to help determine the extent to which changes to span of service caused a greater ridership response (positive or negative) than was experienced on other routes. This approach, which produces adjusted ridership figures, helps determine whether a route that experienced a span of service change over-performed or underperformed in terms of ridership when compared to the bus system average during the measured time period. For example, three routes undergoing a span of service increase that resulted in an average ridership improvement of ten percent during unaltered hours in a transit system that as a whole experienced a ridership increase of three percent during the same time period would have experienced an adjusted ridership increase of seven percent.

However, while adjusting for systemwide ridership changes helps avoid overstating the change in ridership that routes experiencing a span change may have encountered, it could instead result in understating the change experienced, relative to the rest of the transit system. This potential complication occurs when significant service increases or decreases are implemented elsewhere in the transit system, as the span changes studied would be adjusted based on systemwide changes that included increased service. Therefore, the results of the span changes analyzed include both adjusted and unadjusted ridership changes during unaltered hours. 


\section{FINDINGS AND RESULTS}

Multiple attempts were made to contact the 65 identified transit agencies that met the criteria outlined for this research effort. In total, nine agencies successfully provided data on 39 eligible span changes that form the basis for this study.

\section{Results by Span Change Type}

A total of 24 span increases and 15 span decreases were analyzed. Of the 24 span increases, ridership increased by an average of $12.4 \%$ during unaltered hours; 18 of the 24 samples experienced ridership increases during unaltered hours while six samples actually posted a decrease, although the decrease in three of those six samples was negligible (less than one percent). When adjusted to account for systemwide ridership changes, the percent increase during unaltered hours drops to $3.4 \%$; adjusted ridership during unaltered hours increased in 16 of the 24 samples while decreasing in the other eight cases, although three cases of decreases and two cases of increases were negligible.

Of the 15 span decreases that were analyzed, ridership (unadjusted) during unaltered hours was essentially unchanged on average, decreasing by just $0.1 \%$; 10 of the 15 samples experienced ridership increases during unaltered hours while five samples posted a decrease, although three of the increases and one of the decreases were less than one percent. When adjusted to account for systemwide ridership changes, the percent change during unaltered hours becomes $-1.5 \%$; adjusted ridership during unaltered hours increased in eight while decreasing in seven of the 15 analyzed cases (one of the increases was negligible).

Within both categories, however, individual samples exhibited a wide range of results, as illustrated in Figures 1 and 2, which show the distribution of percent changes in ridership (unadjusted and adjusted) following a span change. While the average span increase resulted in adjusted ridership increases during unaltered hours of $3.4 \%$, this average was comprised of experiences ranging from a $30.4 \%$ increase to a $19.6 \%$ decrease. The five instances of an adjusted ridership decline during unaltered hours after a span of service increase could be considered counter-intuitive results, as the expectation would be

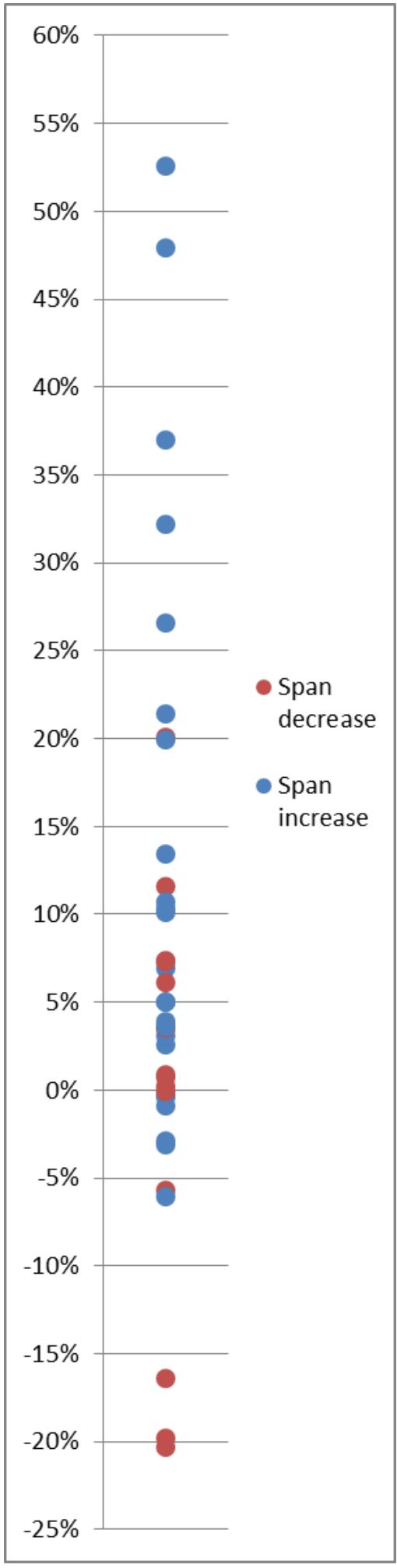

Figure 1. Percent change in ridership during unaltered hours following a span of service change. 
that adjusted ridership during unaltered hours would at least remain neutral (if not increase) when a span change takes place. Similarly, although the average was a fairly small $1.5 \%$ decrease, span decreases resulted in adjusted ridership changes during unaltered hours ranging from a $25.4 \%$ decline to an $18.4 \%$ increase. Adjusted ridership during unaltered hours decreased by more than one percent in 7 of the 15 span decrease samples analyzed, but also increased by more than one percent in seven other span decrease samples (the last remaining sample experienced a negligible increase).

\section{Results by Agency}

Many agencies were only able to provide data on one or a few span of service increases or decreases, making it especially difficult to ascribe much of an agency-level trend to the results, so findings in this section are necessarily limited. Generally, agencies varied significantly in the response observed to span of service changes, based on these very limited samples.

On average, Foothill Transit, which operates in eastern Los Angeles County, experienced the greatest increase in ridership during unaltered hours following a span of service increase. For Foothill Transit, these span increases occurred at a time when systemwide ridership increased by $22.2 \%$ between January and February 2013 to January and February 2014. On average, the eight Foothill Transit routes that received a span increase during the study period experienced a $28.9 \%$ increase in ridership during unaltered hours, meaning the adjusted increase for routes experiencing a span of service improvement was $6.7 \%$. It is worth noting that Foothill Transit implemented the largest set of span of service improvements on a single date of any transit agency that was able to successfully provide data for this research. Foothill Transit was also the only agency studied to implement a span of service increase during mid-day hours, with weekday mid-day service added on three routes. Still, despite the overall impressive results, two of the six routes actually experienced a decrease in ridership during unaltered hours after adjusting for the $22.2 \%$ systemwide ridership gains, while a third route was essentially unchanged. These results may change, however, as more time passes after implementation; in contrast to most agencies, data used to evaluate ridership after the span change was from just a few months after implementation, meaning the increases had little time to mature and potentially attract more ridership. This limitation of the Foothill Transit data means that the strong

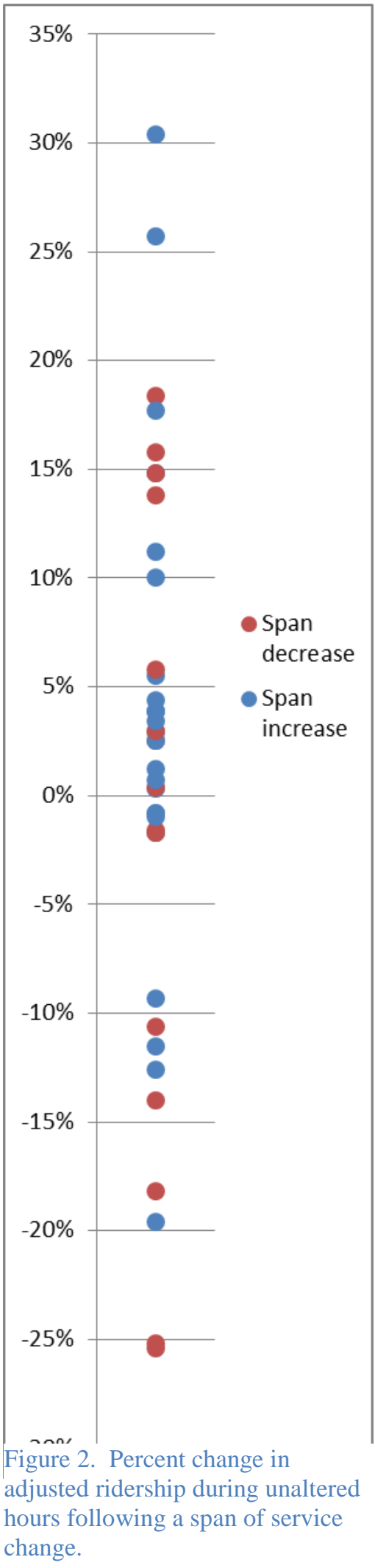


increases should be regarded as particularly impressive. A follow-up study would be necessary to determine the full extent of ridership increases that these routes will experience.

Regional Transit in Sacramento, California provided the second greatest number of samples. Regional Transit provided data for five span increases and three span decreases. All of these increases affected weekday evening service, and three of the five involved a partial or full restoration of a span of service that was reduced just over two years prior -a condition that was unique amongst the studied span changes. On average, ridership on the five routes during unaltered hours increased by $3.8 \%$, or $1.8 \%$ after adjusting for an average $2 \%$ systemwide ridership increase; four of the five routes experienced an increase in adjusted ridership during unaltered hours.

The agency that provided the largest number of samples of span decreases was the Regional Transportation Commission of Southern Nevada (RTC). Of the four samples provided, ridership decreased by an average of $4.6 \%$ during unaltered hours after adjusting for systemwide ridership changes. However, these results varied significantly, with adjusted route ridership on one route actually increasing by $3.0 \%$ during unaltered hours while another route experienced an $18.2 \%$ decline. The other two routes experienced very modest declines of $1.6 \%$ and $1.7 \%$ during unaltered hours after adjusting for systemwide ridership changes.

The remaining agencies were able to provide no more than three instances of span increases or span decreases, implying that analysis is best focused on reviewing results by other categories combined with data from other agencies.

\section{Results by Time of Day Affected}

The span changes enacted can be divided into six logical categories based on the time periods involved. These six categories are listed below, along with the quantity of samples from each time period, although note that individual samples can belong to multiple affected time periods:

- Start of the service day (first trips): two increases, four decreases

- End of the service day (last trips): 18 increases, 12 decreases

- Middle of the service day (trips between traditional morning and afternoon peak hours): three increases, one decrease

- Overnight service (new/former 24-hour service): two increases, one decrease

- Saturday service (entire day): two increases, one decrease

- Sunday service (entire day): one increase, one decrease

As the above list demonstrates, span changes that affected the end of the service day (last trips) were by far the most common amongst the analyzed samples. Span changes affecting the end of the service day actually demonstrated slightly stronger counter-intuitive results than span increases or span decreases as a whole; on average, adjusted ridership increased by $1.6 \%$ during unaltered hours (or an $8.5 \%$ unadjusted increase during unaltered hours) in the 18 span increases affecting the end of the service day, but adjusted ridership also increased by $1.3 \%$ during unaltered hours (or a 3.7\% unadjusted increase during unaltered hours) in the 12 span decreases that affected the end of the service day.

Perhaps the most notable effects regarding a particular time period come from the middle of the service day. While the sample is very small (just three increases and one decrease), all three of the span increases that involved launching mid-day service and thereby eliminating gaps in service between morning and afternoon peak hours experienced a large increase in adjusted 
ridership during unaltered hours, averaging a 22\% increase, or a dramatic $44.2 \%$ increase during unaltered hours without adjusting for systemwide ridership changes. Similarly, the one available sample of a span decrease during mid-day hours (eliminating service between the traditional morning and afternoon peak) experienced a $25.2 \%$ decline in adjusted ridership during unaltered hours $(20.3 \%$ unadjusted decrease during unaltered hours).

Results by other time periods affected generally offered mixed or conflicting results, which is likely due to the very small sample sizes. Additionally, span changes during certain times of day, particularly those affecting the start of the service day, often or exclusively occurred along with span changes during other times of day as well, making it impossible to ascribe the effects of the changes to these specific time periods.

\section{Results by Span Change Duration}

The magnitude of change to the span duration also appears to affect the ridership response during unaltered hours. Table 1 divides the span increases into two equal categories based on span change duration $(50 \%$ of span increase samples included two and a half hours of added service or more, while the other $50 \%$ of span increase samples included less than two and a half hours of added service). Span decreases are divided into three equal categories, also based on span change duration.

\begin{tabular}{|l|l|l|}
\hline \multicolumn{2}{|l|}{ TABLE 1: Results of Span of Service Changes by Span Change Duration } \\
\hline & $\begin{array}{l}\text { Adjusted Ridership Increase } \\
\text { During Unaltered Hours }\end{array}$ & $\begin{array}{l}\text { Unadjusted Ridership Increase } \\
\text { During Unaltered Hours }\end{array}$ \\
\hline $\begin{array}{l}\text { Span increases of more than } \\
\text { two and a half hours }\end{array}$ & $4.1 \%$ & $19.9 \%$ \\
\hline $\begin{array}{l}\text { Span increase of less than } \\
\text { two and a half hours }\end{array}$ & $2.6 \%$ & $5.0 \%$ \\
\hline $\begin{array}{l}\text { Span decrease of two hours } \\
\text { and fifteen minutes or more }\end{array}$ & $-11.0 \%$ & $-12.3 \%$ \\
\hline Span decrease of two hours & $-6.5 \%$ & $5.7 \%$ \\
\hline $\begin{array}{l}\text { Span decrease of one and a } \\
\text { half hours or less }\end{array}$ & $13.1 \%$ & $6.4 \%$ \\
\hline
\end{tabular}

The results in Table 1 indicate that longer span of service increases resulted in greater ridership increases during unaltered hours and vice versa. Similarly, larger span decreases resulted in greater ridership losses during unaltered hours. The shortest duration of span decreases (one and a half hours or less) actually resulted in a ridership increase, perhaps suggesting many customers were able to adjust by using unaltered trips. This indicates a need for further research.

\section{Results for Last Unaltered Hour of Service for Each Change}

Thus far, the results discussed have pertained to all unaltered hours for the entire service day. However, ridership during the last hour of unaltered service prior to an evening span increase or span decrease could potentially produce different results than other unaltered hours of the day. 
As discussed previously, logical arguments could be made that ridership may increase or decrease in the last unaltered hour of the service day prior to a span change.

\begin{tabular}{|l|l|l|}
\hline \multicolumn{2}{|l|}{ TABLE 2: Results of Evening Span of Service Changes for Last Unaltered Hour of Service } \\
\hline & $\begin{array}{l}\text { Adjusted Ridership Increase } \\
\text { During Unaltered Hours }\end{array}$ & $\begin{array}{l}\text { Unadjusted Ridership } \\
\text { Increase During Unaltered } \\
\text { Hours }\end{array}$ \\
\hline $\begin{array}{l}\text { Ridership change from span } \\
\text { decrease }\end{array}$ & $3.4 \%$ & $5.8 \%$ \\
\hline $\begin{array}{l}\text { Range of ridership change } \\
\text { from span decrease }\end{array}$ & $-54.6 \%$ to $63.7 \%$ & $-29.0 \%$ to $65.2 \%$ \\
\hline $\begin{array}{l}\text { Standard deviation of } \\
\text { ridership change from span } \\
\text { decrease }\end{array}$ & $30.4 \%$ & $26.2 \%$ \\
\hline $\begin{array}{l}\text { Ridership change from span } \\
\text { increase }\end{array}$ & $12.7 \%$ & $19.6 \%$ \\
\hline $\begin{array}{l}\text { Range of ridership change } \\
\text { from span increase }\end{array}$ & $-43 \%$ to $124.8 \%$ & $-20.8 \%$ to $126.9 \%$ \\
\hline $\begin{array}{l}\text { Standard deviation of } \\
\text { ridership change from span } \\
\text { increase }\end{array}$ & $35.6 \%$ & $36.3 \%$ \\
\hline
\end{tabular}

Table 2 demonstrates that span decreases partially or exclusively involving evening service tend to produce a minor ridership increase during the last unaltered hour of service, but the experiences vary greatly. Span increases also exhibit tremendous variation in ridership response, but on average, the last unaltered hour of service experiences substantial growth.

\section{Difference between Adjusted and Unadjusted Ridership}

The difference between adjusted and unadjusted increases during unaltered hours bears emphasis. The results that have been discussed above are based on adjusted ridership, which in many cases significantly reduces the change in ridership on the routes analyzed. As noted earlier, the actual increase in ridership during unaltered hours for routes that experienced a span increase was a seemingly high $12.4 \%$, which is what customers and operators on unaltered trips would have observed. However, systemwide ridership increased by an average of $9.1 \%$ between the same dates, and thus the adjusted increase during unaltered hours was a much more modest $3.4 \%$.

\section{ANALYSIS AND CONCLUSION}

Regarding the central question of this research -to what extent bus route span of service changes affect ridership during unaltered hours -the preponderance of evidence presented here suggests 
that ridership does, on average, increase during unaltered hours when span of service is increased. However, while there was a considerable degree of variation amongst the 15 span decreases analyzed, on average, the evidence demonstrates that routes experiencing a span of service decrease encountered little to no change in ridership during unaltered hours.

There are several possible explanations for why ridership during unaltered hours might actually increase when the span of service on a route is reduced. Reasons supplied by agency staff for specific such occurrences include that connecting routes had seen improvements, making an affected route more attractive in the process; that riders previously using service during hours that were eliminated shifted to remaining hours of service instead; that natural variation in daily ridership and amongst trips sampled with APC-equipped vehicles (which, for some agencies, is the minority of the fleet) was responsible, particularly for routes with very low overall ridership; and that changes implemented elsewhere in the transit system caused a small percentage of riders from other transit lines to shift to otherwise reduced routes. These responses indicate that no one single explanation is universally applicable when ridership increases during unaltered hours following a span decrease. Additionally, while some agencies encountered ridership increases during unaltered hours after span decreases, several others did experience significant ridership loss.

The fact that ridership increased slightly on the last unaltered trips prior to an evening span of service decrease suggests that at least some customers do in fact simply shift to an earlier trip when their preferred trip is eliminated. However, the modest increase in ridership on such trips is not nearly enough to compensate for the loss of ridership from all of the riders that previously used trips that were eliminated; adjusted ridership increased by $3.4 \%$ on the last unaltered trips of the evening following an evening span decrease, but overall adjusted ridership (including both altered and unaltered hours) on the same routes decreased by $3.7 \%$. Additionally, of course, such modifications in customer riding behavior are by definition not the preferred choice of customers.

Notably, the ridership growth observed on the last unaltered trips prior to a span increase was actually much higher than in instances of span decreases. This indicates that when span of service is extended, many of the customers traveling on the newly added hours of service are making trips that previously did not occur on transit; ridership was added, rather than just shifting away from what were previously the last trips of the evening. Again, this is consistent with the results observed from the Athens, Greece and Melbourne, Australia cases discussed earlier. These results, combined with the overall adjusted increase in ridership during all unaltered hours of $3.4 \%$, or $12.4 \%$ without adjusting for systemwide ridership changes, suggests that span of service increases are a reasonably effective means of growing overall transit ridership.

Interestingly, of the agencies studied, the agency that implemented the greatest number of span increases, with the greatest duration of hours added, is also the agency that experienced the greatest overall ridership response to span increases: Foothill Transit in Los Angeles County. A key remaining question is whether implementation of a package of span improvements of several hours on multiple routes produces some type of synergistic effect that results in greater ridership gains than would have occurred if the changes were implemented individually. Unfortunately, due to the paucity of such data, a broader search of agencies -likely including at least the entire United States, if not internationally -would be necessary to better investigate this hypothesis. Still, considering that the closest example of a package of improvements resembling the Melbourne experience produced similarly impressive ridership increase results, it seems there is 
reason to suspect the possibility of a strong ridership response from a large package of span of service increases.

The results of this study demonstrate that on average, ridership during unaltered hours increases noticeably following a span of service increase but decreases very modestly, if at all, following a span of service decrease. However, this research specifically examined the ridership impacts on unaltered hours; total ridership on affected routes -meaning ridership that includes the altered hours for which service was added or eliminated -changes by much more than unaltered hours. Overall adjusted ridership on routes that experienced a span decrease declined by $6.1 \%$, whereas overall adjusted ridership on routes that experienced a span increase saw growth of $12.6 \%$. Indeed, it is the hours that are directly affected by span changes -when customers either lose or gain service -that have an obvious and critical effect on riders, and are the traditional focus of study regarding span of service changes; this research regarding ridership impacts on unaltered hours in no way seeks to diminish or distract from the importance of that topic. Rather, the goal of this research was simply to determine if there is another factor to consider -ridership impacts to unaltered hours, instead of just hours directly altered -during a potential span of service change. When evaluating potential span changes, agencies should primarily consider the direct impacts to customers, either in the form of reduced or enhanced mobility, and then consider the potential changes to ridership during unaltered hours explored in this research as a form of secondary guidance.

The research results outlined in this paper provide guidance on some factors that may help increase the ridership response during unaltered hours following a span of service change. Span of service changes where mid-day service is introduced or eliminated exhibited the greatest changes in ridership during unaltered hours; this suggests agencies should prioritize mid-day span increases, or the preservation of mid-day service when considering span decreases, to achieve the largest possible ridership gains (or avoid the largest ridership reductions) during unaltered hours. Large bundling of span increases also appear to produce the strongest possible ridership response; agencies should perhaps consider bundling several span of service increases into a marketable package for which some positive publicity can be gained. Furthermore, span of service changes of a greater duration experienced larger ridership changes during unaltered hours, therefore agencies should consider significant span of service increases -by more than two hours -whenever the opportunity is available, although it is recognized that larger span increases will also involve larger increases in operating costs. It must be emphasized that these are all factors that routes experiencing the largest ridership increases following span of service increases all had in common; it is in no way a statement of direct cause and effect. 
1. Transportation Research Board. (2013). TCRP report 165: Transit capacity and quality of service manual ( $3^{\text {rd }}$ ed.). Washington, D.C.: The National Academies Press. Retrieved May, 2014 from http://onlinepubs.trb.org/onlinepubs/tcrp/tcrp_rpt_165ch-05.pdf

2. Newton, C. (2008, October 29). Phoenix cuts early-morning, late-night bus runs. The Arizona Republic. Retrieved May, 2014 from http://www.azcentral.com/arizonarepublic/local/articles/2008/10/29/20081029phxbuses1029. $\underline{\mathrm{html}}$

3. Transportation Research Board. (2004). TCRP report 95: Traveler response to transportation system changes. Chapter 9 -Transit scheduling and frequency. Washington, DC: The National Academies Press. Retrieved May, 2014 from http://onlinepubs.trb.org/onlinepubs/tcrp/tcrp_rpt 95c9.pdf

4. Guttenplan, M., Davis, B., Steiner, R., \& Miller, D. (2003). Planning level areawide multimodal level of service (LOS) analysis: Performance measures for congestion management. Retrieved May, 2014 from http://www.ltrc.lsu.edu/TRB_82/TRB2003-000997.pdf

5. Transportation Research Board. (2003). TCRP report 100: Transit capacity and quality of service manual ( $2^{\text {nd }}$ ed.). Washington, D.C.: The National Academies Press. Retrieved from http://onlinepubs.trb.org/onlinepubs/tcrp/tcrp100/part\%203.pdf

6. Crockett, C. E. (2002). A process for improving transit service connectivity. Massachusetts Institute of Technology. Retrieved May, 2014 from http://dspace.mit.edu/bitstream/handle/1721.1/39087/52190620.pdf?sequence=1

7. Center for Urban Transportation Research (2000). 1999 transit customer satisfaction index. University of South Florida. Retrieved May, 2014 from http://ntl.bts.gov/lib/11000/11000/11031/392-10.pdf

8. Mamun, S. (2011). Public transit accessibility and need indices: Approaches for measuring service gap. University of Connecticut. Retrieved May, 2014 from http://digitalcommons.uconn.edu/gs_theses/58/

9. Transportation Research Board. (2007). TCRP report 111: Elements needed to create high ridership transit systems. Washington, D.C.: The National Academies Press. Retrieved May, 2014 from http://onlinepubs.trb.org/onlinepubs/tcrp/tcrp rpt 111.pdf

10. Currie, G., \& Loader, C. (2009). High ridership growth from extended transit service hours. Transportation Research Record: Journal of the Transportation Research Board, 2110, 120127. doi: 10.3141/2110-15

11. Veliou, E., Kepaptsoglou, K., \& Karlaftis, M. (2010). Night-time operations in transit systems: Evaluating the Athens Metro owl services. Journal of Public Transportation, 13(3), 79-100. Retrieved May, 2014 from http://www.nctr.usf.edu/wpcontent/uploads/2011/02/JPT13-3Veliou.pdf

12. Loader, C., \& Stanley, J. (2009). Growing bus patronage and addressing transport disadvantage -The Melbourne experience. Transport Policy, 16(3), 106-114. http://dx.doi.org/10.1016/j.tranpol.2009.02.001 